\title{
Editorial: Geospatial Data Capturing, Processing, Analysis, and Visualization in Agro-Geoinformatics
}

\author{
Carlos Granell $^{1 *}$, Sven Casteleyn ${ }^{1}$ and Clement Atzberger ${ }^{2}$ \\ ${ }^{1}$ GEOTEC Research Group, Institute of New Imaging Technologies, Universitat Jaume I of Castellón, Castellón, Spain, \\ ${ }^{2}$ Department of Landscape, Spatial and Infrastructure Sciences, University of Natural Resources and Life Sciences, Vienna, \\ Austria
}

Keywords: remote sensing and GIS technology, Agro-Geoinformatics, crop monitoring, precision agriculture, sustainable agriculture

\section{The Editorial on the research topic}

Geospatial Data Capturing, Processing, Analysis, and Visualization in Agro-Geoinformatics

Due to the ever-increasing availability of remotely sensed data, and accompanying advances in image analysis, data storage, and processing solutions, a wealth of actionable data is now available for various stakeholders, such as farmers, authorities and agro-service providers. In agriculture, such geodata can be deployed for applications at various spatial scales such as:

\section{OPEN ACCESS}

Edited by:

Bronwyn Harch,

Queensland University of Technology,

Australia

Reviewed by:

Daniela Cocchi,

University of Bologna, Italy

*Correspondence:

Carlos Granell

carlos.granell@uji.es

Specialty section:

This article was submitted to

Environmental Informatics,

a section of the journal

Frontiers in Environmental Science

Received: 08 September 2015 Accepted: 10 November 2015 Published: 09 December 2015

Citation:

Granell C, Casteleyn S and

Atzberger C (2015) Editorial:

Geospatial Data Capturing,

Processing, Analysis, and Visualization

in Agro-Geoinformatics.

Front. Environ. Sci. 3:76

doi: 10.3389/fenvs.2015.00076
- crop monitoring and management (Pinter et al., 2003; Atzberger, 2013),

- precision agriculture (Moran et al., 1997; Gebbers and Adamchuk, 2010; Lee et al., 2010),

- alerting and forecasting systems (Doraiswamy et al., 2003; Rembold et al., 2013),

- sustainable resource protection (Baret et al., 2007),

- ecological farming and sustainable intensification (Garnett et al., 2013),

- traceability of products (Opara, 2003),

- policy steering (Palm et al., 2014),

- index- and claim-based insurances (de Leeuw et al., 2014).

The field of Agro-Geoinformatics studies and advances the key enabling technologies, such as Information and Communication Technologies (ICT), Computer Science (CS), and Geographical Information Systems (GIS), with as ultimate goal to create agro-software systems and tools that tackle the above mentioned challenges. This Research Topic aims to study the latest web developments, along with methods and technologies in geospatial data processing, analysis and visualization, to advance the state-of-the-art in Agro-Geoinformatics.

For this Research Topic, we collected three articles reflecting recent innovations in AgroGeoinformatics. We open with a review article that explores the potential of satellite-derived crop temporal metrics in yield gap assessments in smallholder cropping (Duncan et al.). The authors study the potential added value and limitations of time series (crop phenology) throughout the following typical workflow: identification of croplands, yield estimation, yield gap estimation, applicability of temporal information in yield gap assessments, causation, and closure of yield gaps. Existing approaches are discussed at each stage of the workflow. The authors conclude that, on a practical level, the spatial resolution of remote sensing data with daily global coverage is too coarse-grained to capture the heterogeneity and local variability of production in smallholder landscapes. To overcome this limitation, the authors propose a future research agenda based on fine spatial resolution crop phenology, either via data fusion or through new sensors (e.g., Sentinel-2). 
This review sets the stage for the following research articles.

Vuolo et al. present an evaluation of geospatial technologies and Earth Observation (EO) data applied to irrigation water management in a semi-arid agricultural area in Lower Austria. The authors utilize EO data to map crop evapotranspiration and Web-GIS technologies to deliver personalized irrigation advices to farmers. The Web-GIS allows a web-based data analysis and interactive map visualization that are used for decisionsupport. To perform their cost-benefit analysis, authors compare irrigation volumes estimated from satellite imaginary with the irrigation supplied by farmers during a demonstration campaign in 2013. The results indicate that the amount of irrigation water provided equals the maximum amount required by the crop, thus leaving the possibility for optimizing irrigation and saving on cost of water and energy for pumps. A qualitative evaluation indicates a positive attitude of farmers toward the provided EO-based data applied for irrigation water management, and a willingness to pay for the information.

Rembold et al. present the latest developments regarding (personal, non-exclusive and royalty-free license) software specifically dedicated to the analysis of time series data: SPIRITS. The software assists experts in analyzing remotely sensed image time series for crop monitoring mostly recorded at high temporal

\section{REFERENCES}

Atzberger, C. (2013). Advances in remote sensing of agriculture: context description, existing operational monitoring systems and major information needs. Remote Sens. 5, 949-981. doi: 10.3390/rs5020949

Baret, F., Houles, V., and Guerif, M. (2007). Quantification of plant stress using remote sensing observations and crop models: the case of nitrogen management. J. Exp. Bot. 58, 869-880. doi: 10.1093/jxb/ erl231

de Leeuw, J., Vrieling, A., Shee, A., Atzberger, C., Hadgu, K. M., Biradar, C. M., et al. (2014). The potential and uptake of remote sensing in insurance: a review. Remote Sens. 6, 10888-10912. doi: 10.3390/rs61110888

Doraiswamy, P. C., Moulin, S., Cook, P. W., and Stern, A. (2003). Crop yield assessment from remote sensing. Photogr. Eng. Remote Sens. 69, 665-674. doi: 10.14358/PERS.69.6.665

Garnett, T., Appleby, M. C., Balmford, A., Bateman, I. J., Benton, T. G., Bloomer, P., et al. (2013). Sustainable intensification in agriculture: premises and policies. Science 341, 33-34. doi: 10.1126/science. 1234485

Gebbers, R., and Adamchuk, V. I. (2010). Precision agriculture and food security. Science 327, 828-831. doi: 10.1126/science.1183899

Lee, W. S., Alchanatis, V., Yang, C., Hirafuji, M., Moshou, D., and Li, C. (2010). Sensing technologies for precision specialty crop production. Comput. Electron. Agric. 74, 2-33. doi: 10.1016/j.compag.2010.08.005

Moran, M. S., Inoue, Y., and Barnes, E. M. (1997). Opportunities and limitations for image-based remote sensing in precision crop management. resolution and medium to low spatial resolution. Monitoring vegetation conditions is a key aspect to enable sustainable agriculture, and the analysis of time series data reflecting vegetation status in near real-time over large areas is crucial in understanding crop evolution. Obviously, there is also a close link to drought monitoring. The paper overviews novelties in SPIRITS that help toward this aim. Next to more technically oriented features, the authors also explore new visualizations such as matrix charts for comparing, interpreting and analyzing remote sensing-based time series data. To conclude, the authors forecast new developments in SPIRITS, and point out the most important challenges for SPIRITS and other satellite image processing tools.

\section{AUTHOR CONTRIBUTIONS}

CG, SC, and CA all contributed to the conception and drafting of this manuscript.

\section{ACKNOWLEDGMENTS}

This work has been partly funded by the European Union Seventh Framework Programme (FP7-SPACE/2007-2013) project ERMES (grant agreement $n^{\circ} 606983$ ).

Remote Sens. Environ. 61, 219-346. doi: 10.1016/S0034-4257(97) 00045-X

Opara, L. U. (2003). Traceability in agriculture and food supply chain: a review of basic concepts, technological implications, and future prospects. Food Agric. Environ. 1, 101-106.

Palm, C., Blanco-Canqui, H., DeClerck, F., Gatere, L., and Grace, P. (2014). Conservation agriculture and ecosystem services: an overview. Agric. Ecosyst. Environ. 187, 87-105. doi: 10.1016/j.agee.2013.10.010

Pinter, P. J. Jr., Hatfield, J. L., Schepers, J. S., Barnes, E. M., Moran, M. S., Daughtry, C. S. T., et al. (2003). Remote sensing for crop management. Photogr. Eng. Remote Sens. 69, 647-664. doi: 10.14358/PERS.69.6.647

Rembold, F., Atzberger, C., Savin, I., and Rojas, O. (2013). Using low resolution satellite imagery for yield prediction and yield anomaly detection. Remote Sens. 5, 1704-1733. doi: 10.3390/rs5041704

Conflict of Interest Statement: The authors declare that the research was conducted in the absence of any commercial or financial relationships that could be construed as a potential conflict of interest.

Copyright (C) 2015 Granell, Casteleyn and Atzberger. This is an open-access article distributed under the terms of the Creative Commons Attribution License (CC BY). The use, distribution or reproduction in other forums is permitted, provided the original author(s) or licensor are credited and that the original publication in this journal is cited, in accordance with accepted academic practice. No use, distribution or reproduction is permitted which does not comply with these terms. 